\title{
The Role of Health Care Professionals in Providing Smoking Cessation Advice in Najran Armed Forces Hospital, KSA
}

\author{
Imed Harrabi ${ }^{1, *}$, Fawaz al $\mathrm{Harbi}^{2}$ and Saad al Ghamdi ${ }^{1}$ \\ ${ }^{I}$ Family and Community Medicine Center, Najran Armed Forces Hospital, Najran, KSA \\ ${ }^{2}$ Department of Internal Medicine, Najran Armed Forces Hospital, Najran, KSA
}

\begin{abstract}
Background: Smoking is an established risk factor for many diseases and is one of the most important public health problems worldwide. According to the WHO, medical and paramedical staff can influence positively or negatively the smoking habits of a community.

Objective: To explore the predictors of providing smoking cessation advice by medical and paramedical staff.

Methods: We have conducted a cross-sectional study from April, 2014 through May, 2014 in Najran Armed Forces Hospital. Data collection was done using an anonymous, self-administered questionnaire.

Results: The study included 128 health care professionals. The mean age and standard deviation of the study group was $33.8 \pm 8.10$ years. The overall prevalence of tobacco use among medical and para-medical staff amounted to $21.1 \%$. The prevalence among male health care providers amounted to $37.5 \%$ compared to $9.4 \%$ among females. The highest prevalence of tobacco use was among physicians (33.3\%) followed by technicians $(24.2 \%)$ and nurses (11.3\%). More than $16 \%$ of the medical and paramedical staff didn't at all ask patients about their smoking status and only $40 \%$ of them do that from time to time. Nurses were found to be significant predictors in providing smoking cessation advice to patients compared to physicians $(\mathrm{aOR}=5.21,95 \% \mathrm{CI}: 1.1-25.1)$.

Conclusion: The prevalence rate of smoking habit is still higher among persons who understand the related problems of smoking. Nurses are more active than doctors in providing tobacco cessation advice to their patients.
\end{abstract}

Keywords: Counseling, Global Youth Tobacco Survey, health care, health staff, smoking cessation, smoking habit.

\section{INTRODUCTION}

Smoking is an established risk factor for many diseases and is one of the most important public health problems worldwide. It is a major preventable risk factor of non communicable chronic diseases mortality [1].

Smoking is associated with many health issues occurring after a long period of tobacco use. In general, smoking habit is associated with high risk behaviors especially among young population [2].

The World Health Organization has reported that more than 4 million annual deaths are attributed to tobacco consumption [3]; this is projected to be 10 million annually in 2030, most of the victims being from developing countries [4]. About $80 \%$ of the 1.1 billion smokers in the world are living in developing countries [5], and this rate continues to rise [3]. In contrast to the fall in tobacco consumption in most high-income countries that is declining by $1 \%$ annually [6], consumption of tobacco-related products is increasing in developing countries by about $3.4 \%$ per year [3].

*Address correspondence to this author at the Family and Community Medicine Center, Najran Armed Forces Hospital, Najran, KSA;

E-mail: imed_harrabi@yahoo.fr
The Global Youth Tobacco Survey reported that the trend for tobacco smoking in the Eastern Mediterranean Region is increasing, along with the use of other forms of tobacco such as shisha (waterpipe); this increase is mostly due to the low price of tobacco in the region and the weak policies of tobacco control [7]. The global tobacco control report, released in 2008, indicated that the smoking habits prevalence among males in the Eastern Mediterranean Region is ranging from $24.8 \%$ to $61.7 \%$, while in females the prevalence ranges from $1.0 \%$ to $7.9 \%$ [1].

According to the WHO, the prevalence of smoking among young population in arab countries differed widely. It varied from 7\% in Oman to 25\% in Saudi Arabia and $53 \%$ in Lebanon [8].

The prevalence of tobacco use among medical and paramedical staff varied widely [9]. According to WHO, doctors and nurses can influence positively or negatively the smoking habit of a community [1]. In general, doctors who smoke tend to be passive in advising patients to stop smoking $[10,11]$. The knowledge of smoking side effects among Health professional smokers is not positively correlated with providing anti-smoking advise to their patients [12]. Independently to their smoking status or attitudes, doctors should integrate in their daily practice 
systematically the provision of brief advise to their current smoker's patients.

Also, all health professionals should be involved actively in the prevention programs targeting tobacco use at the community level because they know the pathological outcome and addictive aspects and consequent difficulties associated of smoking [13].

Tobacco control efforts benefit considerably from health care providers' advice, which largely relates to their awareness of smoking-related diseases, in particular the health hazards of smoking. Medical and para-medical staff is expected to play a pioneering role in smoking cessation efforts.

\section{OBJECTIVE}

To estimate the tobacco use prevalence among medical and paramedical staff in Najran Armed Forces Hospital and to explore the factors associated with providing smoking cessation advice to their patients.

\section{METHODS}

\section{Study Design \& Sample}

The present study targeted health care workers in Najran Armed Forces Hospital. This cross-sectional study was conducted from 10th of April, 2014 through $10^{\text {th }}$ of May 2014. The study participants included a total of 128 health care providers of both sexes.

\section{Data Collection and Procedure}

Anonymous self-administered questionnaires were used to obtain obtain information on socio-demographic background including age, gender, and professional category.

The questionnaire collected data on characteristics and circumstances of smoking habit including quantity, circumstances, and reason for smoking and quitting potentials. The questionnaire was based on a WHO questionnaire and the related literature on the topic.

The participants were encouraged to give frank answers by explaining that the survey is anonymous and the privacy of participants will remain protected.

\section{Data Analysis}

Data were coded, validated, and analyzed using Statistical Package for Social Science (SPSS) for Windows, version 17.0. Descriptive statistics were used to analyze the study variables. Chi-square was calculated. P-value $<0.05$ was considered significant.

Univariate analysis methods were used at 5\% level of significance. Binary logistic regression analysis was performed to identify potential predictors of giving smoking cessation advices including age, gender, nationality and degree of awareness of harmful effects of smoking.

\section{RESULTS}

The present study included 128 health care professionals. They were 40 males and 88 females (Table 1). The mean age was $33.8 \pm 8.10$ years with statistical difference between males and females (36.21 \pm 8.79 years among males vs 32.74 \pm 7.59 years among females; $p=0.03$ ).

The sample included 77 nurses $(60.1 \%), 33$ technicians $(25.8 \%)$ and 18 physicians $(14.1 \%)$.

The overall prevalence of tobacco use among medical and para-medical staff amounted to $21.1 \%$. The prevalence among male health care providers amounted to $37.5 \%$ compared to $9.4 \%$ among females. The highest prevalence of tobacco use was among physicians (33.3\%) followed by technicians $(24.2 \%)$ and nurses (11.3\%).

The age of starting smoking ranged from 14 to 34 years with an average of $21.25 \pm 5.33$ years, with any significant gender differences $(23.08 \pm 5.63$ years among males and $17.86 \pm 2.41$ years among females; $\mathrm{p}=0.01$ ).

Regarding intention to quit smoking, $68.2 \%$ weren't interested in quitting smoking at all and $22.7 \%$ were interested to quit in the next six months (Table 2).

When asked about the comparison between cigarette and shisha's health effects, $13.5 \%$ mentioned "shisha is less harmful than cigarettes" (Table 3 ).

More than $16 \%$ of the medical and paramedical staff didn't at all ask patients about their smoking status and only $40 \%$ of them do that from time to time (Table 4).

When asked, do you advise smokers to stop smoking during your daily practice; more than $35 \%$ do that from time to time or not at all (Table 4).

In a logistic regression model to identify potential predictors of providing smoking cessation advise among medical and paramedical staff, nurses and technicians were found to be significantly better in advising patients not to smoke with a lesser role played by physicians. $(\mathrm{aOR}=5.21$, 95\% CI: 1.1-25.1) (Table 5).

\section{DISCUSSION}

Medical and paramedical staff is in a strategic position to help their patients quit smoking [14]. According to the recent CDC statistics, at least $70 \%$ of smokers visit a physician each year [15]; the majority of them (70\%) are seriously motivated to stop smoking [15]; 70 percent also report a desire to quit and make at least one serious attempt to do so [16]. In addition, smokers cite a physician's advice to quit as an important motivating factor for attempting to quit; brief advice from a physician leads to a spontaneous quit rate of 2 to 4 percent [15]. In the USA, the National Cancer Institute estimates that if 100,000 physicians were to assist 10 percent of their patients who smoke to quit each year, the number of smokers in the United States would decrease at a rate of 2 million people annually.

The prevalence of tobacco use among medical and paramedical staff in the present study $(21.1 \%)$ was similar to 
Table 1: General characteristics of the studied population.

\begin{tabular}{|c|c|c|}
\hline Variable & $\mathbf{N}$ & $\%$ \\
\hline Male & 40 & 31.2 \\
\hline Female & 88 & 68.8 \\
\hline \multicolumn{3}{|c|}{ AGE } \\
\hline$>30$ & 67 & 52.3 \\
\hline \multicolumn{3}{|c|}{ Profession } \\
\hline Physician & 18 & 14.1 \\
\hline Technician & 33 & 25.8 \\
\hline Single & 41 & 33.3 \\
\hline Divorced & 02 & 1.7 \\
\hline \multicolumn{3}{|c|}{ Nationality } \\
\hline Saudi & 20 & 15.7 \\
\hline Non Saudi & 108 & 84.3 \\
\hline
\end{tabular}

Table 2. Smoking status of the studied population.

\begin{tabular}{|c|c|c|}
\hline Habits & $\mathbf{N}$ & $\%$ \\
\hline Non smoker & 102 & 81.6 \\
\hline Ex smoker & 10 & 8.0 \\
\hline Regular smoker & 4 & 2.2 \\
\hline \multicolumn{3}{|c|}{ Shisha Smoking Status $(\mathrm{n}=124)$} \\
\hline Never smoked & 105 & 84.7 \\
\hline Smoked in the past (at least for 3 months, but stopped) & 9 & 7.3 \\
\hline Smoked monthly (once a month, but less than weekly) & 4 & 3.2 \\
\hline Never smoked Shisha and Cigarettes & 97 & 78.9 \\
\hline Smoked Shisha and/or Cigarettes & 26 & 21.1 \\
\hline \multicolumn{3}{|c|}{ Are You Intending to Quit Smoking Shisha or Cigarattes $(n=22)$} \\
\hline Not at all & 15 & 68.2 \\
\hline Next month & 1 & 4.5 \\
\hline Next six month & 5 & 22.7 \\
\hline More than 6 months & 1 & 4.5 \\
\hline
\end{tabular}


Table 3. Knowledge of the studied population about the harmful effects of smoking.

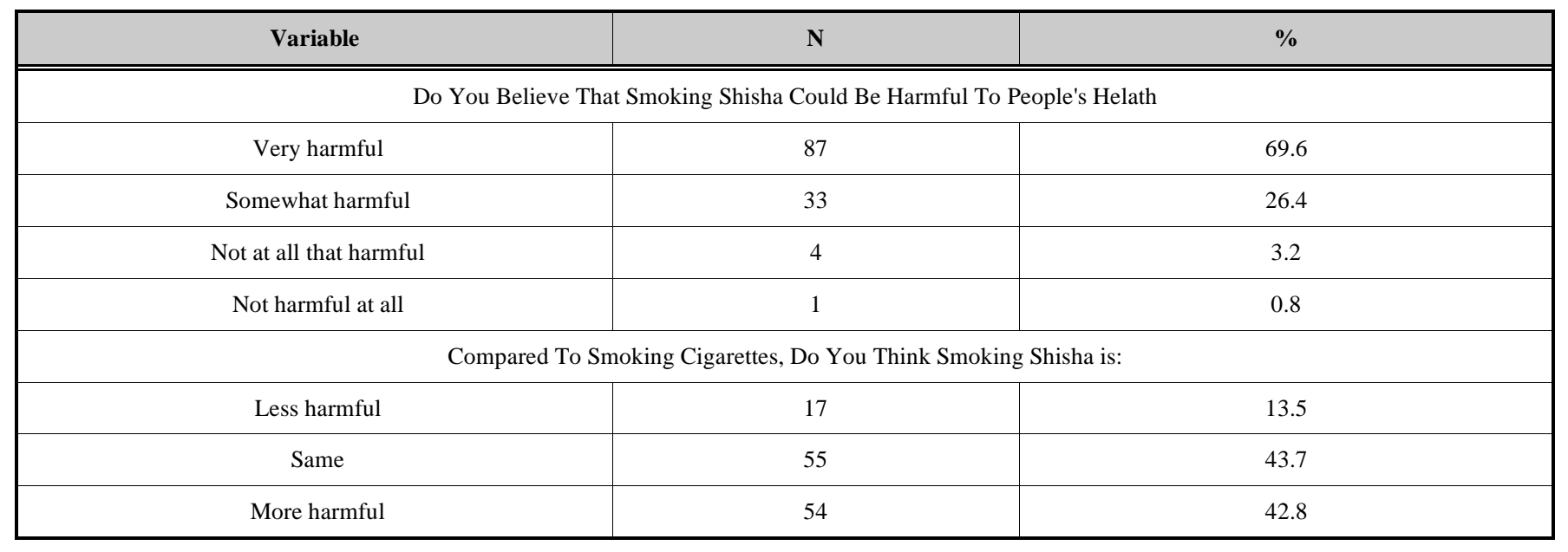

Table 4. Frequency of providing smoking cessation advise.

\begin{tabular}{|c|c|c|}
\hline Variable & $\mathbf{N}$ & $\%$ \\
\hline \multicolumn{3}{|c|}{ In Your Daily Practice, Do You Ask Patients About Their Smoking Status $(n=124)$} \\
\hline Sometimes & 49 & 39.5 \\
\hline Never & 20 & 16.1 \\
\hline Usually & 78 & 62.4 \\
\hline Sometimes & 36 & 28.8 \\
\hline Never & 11 & 8.8 \\
\hline
\end{tabular}

Table 5. Factors associated with providing smoking cessation advise.

\begin{tabular}{|c|c|c|}
\hline Variable & OR (95\%) \\
\hline \hline \multicolumn{2}{|c|}{ Profession } & $(1.1-25.1)$ \\
\hline Physician & 1 & \\
\hline Nurse or Technician & 5.21 & $(0.56-2.71)$ \\
\hline$<30$ & Age & \\
\hline$\geq 30$ & 1 & 1.24 \\
\hline Poor knowledge & Harmful Effects of Smoking Shisha & \\
\hline Good knowledge & 1 & $(0.50-2.56)$ \\
\hline & Gender & \\
\hline Male & 1.13 & $(0.73-6.64)$ \\
\hline
\end{tabular}


Table 5. contd...

\begin{tabular}{|c|c|c|}
\hline Variable & OR (95\%) \\
\hline \hline \multicolumn{3}{|c|}{ Nationality } \\
\hline Saudi & 1 & $(0.73-8.28)$ \\
\hline Non Saudi & 2.21 & \\
\hline Smoker & Smoking Status & $(0.72-6.20)$ \\
\hline Non Smoker & 1 & 2.11 \\
\hline
\end{tabular}

the general adult population rate in Saudi Arabia (11.6$52.3 \%$ with a median of $22.6 \%$ ) [17].

Our survey revealed that male medical and paramedical staff are significantly more smokers than females. Similar trend was observed in previous studies in Saudi Arabia [18] and Arab countries $[19,20]$. Cultural factors may explain the gender differences. According to the article 4.2 of the WHO Framework Convention for Tobacco Control (FCTC), all tobacco control strategies should take into consideration the gender specificities and the involvement of women in all policymaking tobacco control decisions and measures.

In our study, more than $16 \%$ of the medical and paramedical staff didn't at all ask patients about their smoking status and only $40 \%$ of them do that from time to time. Studies show that patients often respond positively to their health care providers counseling them about smoking, even after only brief and simple advice [21,22].

In our study, nurses were more active than doctors for providing smoking cessation advise. Recent studies showed that patients respond very positively with nurses when they talk to them about their health related problems [23].

The results of this study will be of a great interest in order to plan specific interventions targeting especially physicians. The aim of these interventions is to help first physicians smokers to quit smoking and secondary the sensitization of all medical and para-medical staff to be more involved in all smoking cessation activities and opportunities at the hospital and the community levels.

\section{CONCLUSION}

Health care providers include doctors, technicians and especially nurses for their role and image can strongly promote a lifestyle and culture without tobacco among their patients and communities. As part of their activities they can help people by advising, guiding and responding to their questions regarding smoking and its health effects.

\section{CONFLICT OF INTEREST}

The authors confirm that this article content has no conflict of interest.

\section{ACKNOWLEDGEMENTS}

Declared none.

\section{REFERENCES}

[1] WHO. Report on the global tobacco epidemic. Enforcing bans on tobacco advertising. Geneva: WHO 2013.

[2] WHO. Health situation in the South-East Asia Region, 1998-2000. New Delhi: World Health Organization Regional Office for SouthEast Asia 2002.

[3] WHO. Making a difference in people's lives. Geneva: World Health Organization 1999.

[4] CDC. Achievements in public health, 1990-1999. Tobacco use United States, 1990-1999. MMWR 1999, 48(43): 986-93.

[5] World Bank. Global trends in tobacco use. In: Curbing the epidemic: governments and the economics of tobacco control. New York: World Bank 1999; p. 13.

[6] CDC. Smoking and health in the Americas. DHHS 1992. Publication no. 928419.

[7] El Awa F. Tobacco control in the Eastern Mediterranean Region: Overview and way forward. East Mediterr Health J 2008; 14: S123-31.

[8] WHO report on the global tobacco epidemic. Monitor tobacco use and prevention policies. Geneva: World Health Organization 2013.

[9] Abdullah ASM, Husten CG. Promotion of smoking cessation in developing countries: a framework for urgent public health interventions. Thorax 2004; 7: 623-30.

[10] Nazary AA, Ahmadi F, Vaismoradi M, Kaviani K, Arezomandi M, Faghihzadeh S. Smoking among male medical sciences students in Semnan, Islamic Republic of Iran. East Mediterr Health J 2010, 16(2):156-61.

[11] Gil E, et al. Prevalence of smoking among health professionals working in the National Institute of Public Health Care (Insalud). Prevenciondel tabaquismo 2000; 2(1): 22-31.

[12] Richmond R. Teaching medical students about tobacco. Thorax 1999; 54:70-8.

[13] Doyle DB, Burkhardt MA, Copenhaver J, Thach S, Sotak D. Health professions students as research partners in community oriented primary care. J Commun Health 1998; 23: 337-46.

[14] Lancaster T, Bergson G, Stead L. Physician advice for smoking cessation. Cochrane Database Syst Rev 2008; 16(2): CD000165.

[15] Tomar SL, Husten CG, Manley MW. Do dentists and physicians advise tobacco users to quit? J Am Dent Assoc 1996; 127: 259.

[16] Centers for Disease Control and Prevention (CDC). Cigarette smoking among adults-United States, 1999. MMWR 2001; 50: 869.

[17] Bassiony M. Smoking in Saudi Arabia. Saudi Med J 2009; 30: 87681 .

[18] Siddiqui S, Ogbeide D. Profile of smoking amongst health staff in a primary care unit at general hospital in Riyadh, Saudi Arabia. Saudi Med J 2001; 22, 1101-4.

[19] Al-Lawati J, Nooyi S, Al-Lawti A. Knowledge attitudes and prevalance of tobacco use among physicians and dentists in Oman. Ann Saudi Med 2009; 29(2): 128-133. 
[20] El-Khushman H, Sharara A, AL-Laham Y, Hijaz M. Cigarette smoking among health care workers at King Hussein Medical Center. J Hosp Med 2008; 3: 281-4.

[21] Patkar AA, Hill K, Batra V, Vergare MJ, Leone FT. A comparison of smoking habits among medical and nursing students. Chest 2003; 124(4): 1415-20.
[22] Cokkinides VE, Ward E, Jemal A, Thun MJ. Under-use of smoking-cessation treatments: results from the National Health Interview Survey, 2000. Am J Prev Med 2005; 28(1): 119-22.

[23] Sreedharan J, Muttappallymyalil J, Venkatramana M. Nurses' attitude and practice in providing tobacco cessation care to patients. J Prev Med Hyg 2010; 51(2): 57-61.

Received: July 18, 2014

Revised: November 03, 2014

Accepted: November 07, 2014

(C) Harrabi et al.; Licensee Bentham Open.

This is an open access article licensed under the terms of the Creative Commons Attribution Non-Commercial License (http://creativecommons.org/licenses/by$\mathrm{nc} / 3.0 /)$, which permits unrestricted, non-commercial use, distribution and reproduction in any medium, provided the work is properly cited. 